\title{
Deviant Group Membership - Joining, Leaving, and Behavior in Criminal Groups
}

\author{
Raqota Berger ${ }^{1}$ \\ ${ }^{1}$ Center for Criminal and Psychological Studies, Los Angeles, United States \\ Correspondence: Raqota Berger, Center for Criminal and Psychological Studies, Los Angeles, United States.
}

Received: August 6, 2019

doi:10.11114/ijsss.v7i6.4427

\author{
Accepted: August 26, 2019 \\ Available online: September 24, 2019 \\ URL: https://doi.org/10.11114/ijsss.v7i6.4427
}

\begin{abstract}
Each year across the United States hundreds of thousands of individuals become involved in deviant groups, the most common being street gangs. Joining a deviant group is associated with higher rates of criminal offending, serious bodily injury, victimization, and even death. This study collected data from 124 individuals that have joined criminally-based groups at some point in their lives. These groups were identified by respondents as street gangs, crews, biker gangs, prison gangs, drug gangs, and car gangs. Most members joined their groups as teenagers ( $=15)$, and most left their groups during their early adult years. The average time spent in their respective groups was 6 years. The most common reasons for joining their groups was for friendship, family, respect, money, and protection. All respondents were involved in some sort of harmful behaviors while in their groups, the most common being drug and alcohol use, graffiti, vandalism, theft, and violence. Most of the study's respondents had already left their respective groups $(n=70,56.5 \%)$. The top reasons for leaving involved maturity, family responsibilities, parental responsibilities, legal problems, and employment. Generally, members from all types of groups studied stated that the group and lifestyle had a significant impact on their life and development (77\%). Out of the major deviant groups analyzed in the study, it appears that belonging to a street gang may have largest overall impact, $t(113)=2.32$, sig. $=.002$. This study provides further insight and information that could be of use for those working across a range of professions dealing with youth violence, behavioral problems, mental health issues, and education.
\end{abstract}

Keywords: deviant groups, gangs, criminal behavior, joining, leaving

\section{Introduction}

Each year across the United States approximately 400,000 youth join street gangs (Densley, 2019). According to the Federal Bureau of Investigation (FBI, 2019) there are around 33,000 violent motorcycle gangs, prison gangs, and street gangs across the nation that account for around $48 \%$ of all violent crimes committed each year. According to the FBI (2019), there is close to 1.5 million active gang members across the United States and many of these members are involved in ongoing crimes such as gun and drug trafficking, robbery, prostitution, fraud, and human trafficking. Los Angeles has the highest overall number of gang members of any city across the nation. According to the Los Angeles Police Department (LAPD, 2019), there are around 450 active gangs in the city, with a total of over 65,000 members. The LAPD reported that gangs in Los Angeles account for thousands of violent acts each year, including homicide (over 100 each year), robbery, violent assault, and rape.

The question really comes down to why people join these types of groups. What motivates a person to join a deviant or criminal group? What are the risk factors for joining a deviant group? What kinds of behaviors do these individuals often engage in while active in these groups? What motivates one to leave these groups? There are many different reasons as to why a young male or female may make the decision to join a deviant group. There is no single explanation for this, but there are some common factors that clearly play into the decision to join a criminally-based group, such as a street gang. There is also no single type of behavioral pattern that fits each person that joins these types of groups. Each person will follow his or her own path once they join the group. There are also many different reasons as to why members usually make the decision, at some point, to leave their respective groups.

The purpose of this study is to better make sense of why people join deviant groups, what kinds of behaviors they engage in while in these groups, and why most ultimately leave these groups. The study has also been designed to help make sense of how members felt about joining these groups, what kind of impact joining this these groups had on their 
lives, and whether or not they regretted becoming involved in their respective groups. The study will also attempt to make sense of what kinds of youth are the most likely to join these criminal groups and what could potentially be done to help these youth before they become involved in a lifestyle that could potentially damage them for life. The importance of this topic is clear. Thousands of people are murdered each year across the United States by gang members. Many more are victimized in different ways by active members of street gangs, crews, biker gangs, and prison gangs. To best understand the reasons why the nation is facing such a major problem with all of this it is necessary to pay attention to the social, cultural, economic, familial, educational, developmental, and psychological factors that all play a part in this larger cultural problem. By better understanding the causes, risk factors, and motivating forces that compel young people to join deviant groups, concerned professionals will be much better equipped to help deter them and set them on a healthier life path. This study should be of interest to professionals working in areas such as education, mental health, clinical psychology, corrections, juvenile and adult probation, law enforcement, and criminal and forensic psychology.

\section{Literature Review}

There are many different reasons as to why a young male or female may make the decision to join a deviant group (e.g., street gang). Based on the most relevant research, some of the more common reasons appear to involve poor parenting, lack of proper social controls, inadequate schools, lack of positive role models, antisocial socialization experiences, family dysfunction, and having a family member/sibling involved in a deviant group (Bao, 2018; Bishop et al., 2017; Garduno \& Brancale, 2017; Medina, Ralphs, \& Aldridge, 2012). There are different social, psychological, and interpersonal reasons that people are drawn toward a deviant lifestyle. Macfarlane (2018) pointed out that social factors play a major role in placing people at-risk of joining deviant groups, such as negative peer relations and coming from a dysfunctional family environment. In relation to this, Pyrooz, McGloin, \& Decker (2017) found in their research that poor parenting and the intergenerational transmission of gang identity often plays a major role when it comes to a young person becoming involved with a gang.

Researchers have also found additional core reasons as to why one may make the choice to become involved in a dangerous lifestyle associated with membership in a deviant group. Other prominent reasons include drug and alcohol use, bullying, fear, victimization, depression, loneliness, weakening social bonds, and friendship (Merrin, Hong \& Espelage, 2015; Suh, Brashears, \& Genkin, 2016; Weerman, Lovegrove, \& Thornberry, 2014). Identity, status, recognition, and protection also appear to be a strong motivating forces when it comes to joining a deviant group (Bullard \& Reid, 2019; Los Angeles Police Department, 2019). The desire to make money and acquire power are also enticing determinants when it comes to joining a gang (Carson \& Esbensen, 2017; Federal Bureau of Investigation, 2019). In an interesting study on the risk factors behind why young people join gangs, Estrada, Gilreath, Sanchez, \& Astor (2017) found in their sample of 13,484 high-school students that children of military parents that have frequent deployments or relocations are at a significantly higher risk of being involved in a deviant group. The team found that those students that have been in physical altercations or that carry weapons are 2 times as likely to be involved in a gang.

In his extensive work on gangs, Densley (2019) found that youth gang membership is around 2\% nationwide and most members join these types of groups between the ages of 12 to 15. In his review of the extant literature, he found that the most common reasons youth join gangs is because of peer gang membership, early violent behavior, low parental involvement. academic failure, truancy, school dropout, parental criminality, child maltreatment, poverty, and community disorganization. Several researchers have made sense of joining delinquent or criminal groups through the perspectives of social bonds, differential association, strain theory, subcultural theory, control theory, social learning, and conflict theory (e.g., Bishop et al., 2017; Densely, 2019; Schaeffer, 2018). Schools also appear to be a primary place where young people are drawn into gang lifestyles. High-status gang members often use schools as optimal places to influence and recruit new members (Gallupe \& Gravel, 2017). There are many different reasons as to why a person may make the choice to join a deviant or criminal group. There is often a complex combination of risk factors that interact with one another to increase the likelihood that a person may make the decision to go down a certain path in life. Although there are some fairly established risk factors that may motivate one to join a deviant group, there are no certainties when it comes to each particular individual (Carson \& Esbensen, 2017; Estrada et al., 2017).

Being involved in a deviant group can often come with many undesirable and harmful consequences. Although most youth join gangs to seek out friendship, identity, protection, and/or excitement, most will also deal with some very unhealthy and dangerous situations while involved in their groups. Many youths join street gangs for status and protection, but they actually increase their risk of being victimized when they join the group (Gang Reduction and Youth Development, 2019; Weerman et al., 2014). Youth that join deviant and violent groups are at increased risk of facing psychological health problems (e.g., depression, anxiety, post-traumatic stress disorder) and to be seriously physically injured or even murdered (Beresford \& Wood, 2016; Los Angeles Police Department, 2019). Pyrooz et al. 
(2017) explained in their work that membership in a gang often results in negative life consequences and sets in motion an array of emotional, cognitive, and social problems. Being involved in a criminal group significantly increases one's risk of dropping out of school, being unemployed, being victimized, and ultimately becoming incarcerated (Bullard \& Reid, 2019; Densley, 2019; Los Angeles Police Department, 2019).

Most members of deviant groups will eventually leave the group. According to Pyrooz et al. (2017), gang membership tends to be temporary and most will leave at some point during their early adult years. Research shows that most members only stay active for around 1 to 2 years (Densley, 2019; Weerman et al., 2014), although some members are active for much longer (Berger, Abu-Raiya, Heineberg, \& Zimbardo, 2017). There are many different reasons as to why a group member would make the decision to leave the group and lifestyle. According to Densley and Pyrooz (2017), gang members will often signal to others that they are ready to leave the lifestyle. This signaling is an attempt to de-identify with the group by letting others know that they are no longer committed to the group. Some informed others would include law enforcement, fellow gang members, and rival gang members. Some common reasons that members leave their respective groups include procuring employment in the legal workforce, not wanting to go back to jail, recognizing drawbacks of gang lifestyle and violence, accepting help and guidance from others, maturing, and need to change lifestyle (Bullard \& Reid, 2019; Goodwill \& Ishiyama, 2016; Weerman et al., 2014). Others leave the group because they become disillusioned by the lifestyle and what it represents (Roman, Decker, \& Pyrooz, 2017).

One of the most common ways that researchers make sense of why deviant group members leave their respective groups is through the lens of "pushes" and "pulls." Pushes tend to refer to the forces that motivate one to disengage from the group because of things such as disillusionment with lifestyle, burnout, and victimization, whereas pulls refer more to exiting forces associated with being seriously injured (e.g., being stabbed or shot), family responsibilities, religious awakenings, and parenting (Berger et al., 2017; Bullard \& Reid, 2019; Carson \& Esbensen, 2017; Pyrooz et al., 2017). Research by Pyrooz et al. (2017) found that becoming a parent has a profound effect on female gang members and it often serves as the catalyst for exiting the gang lifestyle. Becoming a parent does not have the same "pull" force on males as it does for females. Males are more likely to leave the lifestyle due to being victimized, being incarcerated, or simply growing out of the lifestyle (Berger et al., 2017; Densley \& Pyrooz, 2017; Gang Reduction and Youth Development, 2019). Whatever the reasons are, most members will leave their respective groups at some point (Densely, 2019; Weerman et al., 2014). It is important to understand why these individuals join these groups, what takes place while they are in these groups, and why they leave these groups. Further research in these areas will help interested professionals to better understand these reasons and to be able to more effectively intervene wherever possible.

\section{Methods}

\subsection{Research Design}

The data for this study were collected via a quantitative survey instrument. The survey contained questions that provided responses that ranged from the nominal (discrete) level through the ratio (continuous) level. The instrument took less than 5 minutes to complete. No compensation was given for participating in the study. Deception was not used and all respondents were informed about the nature and purpose of the study prior to filling out the questionnaire. Consent was given by the willingness of the respondents to fill out the survey. To be eligible for the study the respondents needed to be at least 18 years of age and must have been a member of a deviant group at some point in their lives. Initial participants were identified through a local mentoring program and research center. Local law enforcement was also utilized to help recruit participants. The information for the study was collected in a nonrandom manner through purposive and snowball sampling. Due to the nature of the topic (i.e., collecting data from current and former gang members that are/were involved in criminal activities) it was deemed that these two types of sampling techniques would be the most realistic and practical when it came to locating and procuring respondents for the study.

The survey asked participants varying questions about their involvement in a deviant/criminal group, why they joined the group, what kinds of behaviors they engaged in while in the group, and why they left the group (if they had left the group at the time they filled out the instrument). Questions were also asked about their feelings about being in the group, whether or not they would still join the group if they could go back in time, what type of group they joined, how old they were when they joined, and how old they were when they left the group (if they had left the group). Scale items were also included to help with group comparisons and potential inferential comparisons. A scale item was created to collect data on the impact that the group has had on their lives and was set up as, 1 (no impact), 2 (a little), 3 (neutral), 4 (a good amount), to 5 (a great deal). Respondents were also asked about certain demographic variables to allow for group comparisons (e.g., ethnic identity, gender). The design of the study primarily allowed for a statistically-based analysis of the data. The design of the survey limits its ability to probe into more qualitative areas and analyses. The majority of the data were collected in Southern California, although a small portion of the surveys were filled out via the Internet and through phone interviews with respondents living in areas outside of California. 


\subsection{Participants}

Information for the study was collected from 124 respondents that all self-identified as having participated in some kind of deviant or criminal group. The majority of respondents were currently living in various cities across Los Angeles county. The majority of respondents identified as being, or having been, a member in a street gang $(n=96,77.4 \%)$. The remainder of the respondent's affiliations broke down as follows: crew $(n=20,16.1 \%)$, biker gang $(n=3,2.4 \%)$, drug group $(n=2,1.6 \%)$, prison gang $(n=1,0.8 \%)$, car gang $(n=1,0.8 \%)$. The majority of the participants were male $(n=$ $93,75 \%)$. Women made up $21 \%$ of the sample $(n=26)$. A single respondent $(0.8 \%)$ identified their gender as "other." The preponderance of respondents identified as Hispanic $(n=98,79 \%)$ and this is relatively commensurate with the majority of gang members in and around Los Angeles county. The rest of the sample breaks down as: Black $(n=10$, $8.1 \%)$, Asian $(n=5,4.0 \%)$, White $(n=4,3.2 \%)$, and Multiracial $(n=4,3.2 \%)$. Out of the 124 respondents, $70(56.5 \%)$ were no longer involved with the group; 54 respondents (43.5\%) were still actively involved in their respective groups at the time the survey was filled out.

\subsection{Analysis}

A range of analyses were performed on the data. Various descriptive and inferential analyses were executed across the data via the statistical software program SPSS 24 . The categorical variables were properly coded into SPSS to enable subsequent statistical analysis. Continuous data were placed directly into the database as needed to allow for inferential and parametric measures and assessments. A range of descriptive analyses were run on the categorical variables (e.g., measures of central tendency, standard deviations). Various tests and measures employed across the analyses included the one-way analysis of variance (ANOVA), the independent samples t-test, Kruskal-Wallis, Kolmogorov-Smirnov, the median test, and the Mann-Whitney U test. To help shed light on any meaningful associations, correlations were run employing Lambda, Goodman and Kruskal tau, Cramer's V, and Spearman's rho. Various crosstabulations and Chi-Square analyses were run across the appropriate categorical variables of interest. The standard level of statistical significance (.05) was set for all analyses and all tests were two-tailed. Any result that had a higher probability of chance occurrence (i.e., greater than a probability of .05) was deemed to be statistically insignificant and was analyzed accordingly.

If any survey had a particular item that was left blank or that was uninterpretable it was removed from that particular analysis. None of the surveys collected had more than one item left blank or that was not readable. All of the surveys included in the final analysis appeared to have been filled out in an honest and meaningful manner. None of the surveys collected needed to be discarded for lack of candor or apparent dishonesty. Respondents appeared to have a clear understanding of what the survey was asking and what the general topic was about. None of the survey items appeared to cause any discomfort or confusion in the respondents. With this, it is being taken here that the final set of collected data and the analytic results can be regarded as both credible and valid. The foregoing facts of this study have enabled valuable examination of the topic of interest. The subsequent section in this work will shed further analytic light on when people join deviant groups (e.g., age), why they join deviant groups, and the impact that joining these groups have had on their lives. Section 4 has been created to provide further empirical data and analysis on the behaviors, motivations, and differences among and between the highlighted groups and group members. The analytic results have been provided to bring forth the lived experiences and realities of those that have become involved in deviant and criminal groups.

\section{Results}

The average age at the time of joining their respective groups was $15(\mathrm{SD}=3.40)$. The youngest person to join a deviant group was 8 years old at the time of recruitment. The oldest person to join one of these groups was 33 at the time (biker gang). The average age at the time of leaving their respective groups was $21.86(\mathrm{SD}=6.10, \mathrm{Mo}=19)$. The youngest person to leave their group was 13 at the time of exiting. Out of the 70 respondents that have detached from their former groups, the oldest person to leave was 40 at the time of exiting. When asked if they would still join the group if they could turn back time, $54(43.5 \%)$ said that they would and $70(56.5 \%)$ said that they would not. It is important to keep in mind that 54 respondents were still active in their respective groups. These respondents were the one most likely to state that they would still join the group. Those that left the group showed a strong preference for regretting joining the group. Women $(65.4 \%)$ were slightly more likely to regret joining the group than the men $(53.8 \%)$. Again, it is important to note that these are the same percentages that correlate to how many women and men are still active in their groups. That is, virtually all of the women that left the group would make different life choices if they could turn back time. Chi-square tests were run across gender and ethnicity in relation to still being active in their groups and having regrets about joining their groups. None of the tests produced any significant findings. Further examination of the data showed that those from different genders and different ethnic groups essentially felt the same about joining and leaving their groups. Various parametric tests (e.g., ANOVA, $t$-tests) were run across gender and ethnicity in regard to age at 
joining the group, age at leaving the group, and impact that the group had on them. None of these tests produced statistically significant results in regard to gender or ethnicity influencing joining, leaving, or impact of group.

As far as the impact that joining the group had on their lives, most respondents felt that the time spent in the group had a notable effect on their lives and development. On a scale from 1 to 5, the mean score for impact was 4.23 (a good amount, $\mathrm{SD}=1.14)$, the mode was 5 , and the median was also 5 . A total of 74 respondents $(59.7 \%)$ stated that joining the group had a major impact on their lives. Only 5 respondents $(4.0 \%)$ stated that it had no real impact at all on their lives. When asked why they joined the group, the top response was for friendship, followed by respect, a sense of family, money, immaturity, protection, poor parenting, and excitement. Table 1 breaks down the reasons that respondents joined their respective groups. Seeing that almost all respondents joined for more than one reason it makes more sense to provide a full breakdown as opposed to stating a single reason from top to bottom. Note that a few respondents did not fill out some of these questions, so not all of the percentages will come to exactly $100 \%$. Other reasons given by some respondents that are not listed in the table include boredom, fear, and lack of support.

All of the respondents acknowledged that they were involved in some kind of harmful behaviors while they were active in their respective groups. The vast majority also recognized that they were involved in multiple harmful behaviors (93.5\%). The top behaviors that the respondents engaged in were drugs, alcohol, graffiti, vandalism,

and theft. Drug and alcohol use were easily the top two behaviors engaged in across both gender and ethnicity. Almost all of the respondents indicated that they engaged in more than one harmful behavior while in the group so it would make more sense to highlight this as opposed to any single behavior. Table 2 provides the detail on the top 10 kinds of behaviors the respondents engaged in while in their respective groups. The percentages do not add up to exactly $100 \%$ due to a few items being left blank on the survey. No notable differences were detected between ethnic groups, but there were some clear differences between the women and the men. For instance, male respondents were more likely to be involved in behaviors that directly victimized others, such as violence and robbery. Drug and alcohol use were top behaviors for the female respondents. Other less common behaviors engaged in while in the group that are not listed in the table include extortion $(f=10,8.1 \%)$, white-collar crime $(f=4,3.2 \%)$, and sex trafficking $(f=3,2.4 \%)$.

Table 1. Reasons for Joining Deviant/Criminal Groups

\begin{tabular}{|c|c|c|c|c|c|c|c|c|c|}
\hline & Yes & $\%$ & No & $\%$ & & Yes & $\%$ & No & $\%$ \\
\hline Friendship & 73 & 58.9 & 50 & 40.3 & Excitement & 37 & 29.8 & 86 & 69.4 \\
\hline Respect & 68 & 54.8 & 55 & 44.4 & Allure of Lifestyle & 35 & 28.2 & 88 & 71.0 \\
\hline Family & 57 & 46.0 & 66 & 53.2 & Peer Pressure & 27 & 21.8 & 96 & 77.4 \\
\hline Money & 54 & 43.5 & 69 & 55.6 & Immaturity & 19 & 15.3 & 104 & 83.9 \\
\hline Protection & 47 & 37.9 & 76 & 61.3 & Poor Parenting & 14 & 11.3 & 109 & 87.9 \\
\hline Pride & 39 & 31.5 & 84 & 67.7 & & & & & \\
\hline
\end{tabular}

Table 2. Most Common Behaviors While Active in Group

\begin{tabular}{lccccccccc}
\hline & Yes & $\%$ & No & $\%$ & & Yes & $\%$ & No & $\%$ \\
\hline Drugs & 103 & 83.1 & 17 & 13.7 & Violent & 51 & 41.1 & 69 & 55.6 \\
Alcohol & 102 & 82.3 & 18 & 14.5 & Robbery & 41 & 33.1 & 79 & 63.7 \\
Graffiti & 70 & 56.5 & 50 & 40.3 & Burglary & 37 & 29.8 & 83 & 66.9 \\
Vandalism & 61 & 49.2 & 59 & 47.6 & Auto Theft & 35 & 28.2 & 85 & 68.5 \\
Theft & 52 & 41.9 & 68 & 54.8 & Arson & 11 & 8.9 & 109 & 87.9 \\
& & & & & & & & &
\end{tabular}

As stated earlier, 54 out of the 124 respondents were still active in the group at the time the surveys were filled out. Among the 70 respondents that had left their respective groups, the top reason given for leaving was maturity $(n=34,27.4 \%)$. 
This was followed by family responsibilities $(n=29,23.4 \%)$, parental responsibilities $(n=22,17.7 \%)$, legal problems $(n$ $=28,22.6 \%)$, employment/career $(n=19,15.3 \%)$, bored with lifestyle $(n=9,7.3 \%)$, health problems $(n=5,4.0 \%)$, and moving $(n=3,2.4 \%)$. As before, many respondents gave multiple reasons as to why they departed from their groups, but it was clear from the data that growing older, maturing, and taking on new life responsibilities were often the driving forces for change.

Seeing the bulk of the respondents identified with being (or having been) associated with street gangs and crews there were limits placed on any inferential tests that could be run across the various deviant groups. Group sizes were large enough to compare street gangs to crews across several scaled variables. Street gangs and crews can be differentiated in several ways. Chart 1 provides a general comparison to highlight common differences between the two types of groups. Street gangs range from being small to being quite large (e.g., hundreds of members) and they typically span multiple generations. Established street gangs that have existed for decades often have thousands of past and current members. Gangs are often identified by signs and a recognized name. Gangs are typically involved in ongoing criminal activities that have a more profound societal effect than that of crews. Crews often reside somewhere between a "group of friends" and a street gang. Crews are often small (e.g., 5 to 15 members) and they often do not hold a claim to a particular territory. Crews also tend to exist for a relatively short period of time where all members are phase out. It is important to note that these are common characteristic differences and particular groups will vary both within and between.

Independent samples $t$-tests produced significant findings in regard to how old members were when they left the group, $\mathrm{t}(33)=2.09$, sig. $=.002$. Members of street gangs left their groups at an average age of 22, whereas those belonging to crews left at an average age of 18. A further $t$-test also produced significant results in regard to how much of a life impact being in the groups had on those in street gangs compared to those in crews, $t(113)=2.32$, sig. $=.002$. The findings here suggest that those that become involved in street gangs are more impacted overall than those that become members of crews. A $t$-test comparison between the two groups in regard to how old they were when they joined their respective groups did not produce significant differences, $\mathrm{t}(111)=.039$, sig. $=.593$. Members from both groups were often around 14 to 15 years of age when they joined their groups. A Kruskal-Wallis test looking at the impact that being in the group had on one's life produced significant results $(\mathrm{p}=.009)$. This lends further evidence that behaviors and experiences across the various types of groups are not the same. The collected data demonstrate that most individuals that join deviant groups are young when they do so $(\overline{\mathrm{X}}=15)$, that they engage in multiple harmful behaviors while active in the group (e.g., drugs, violence, theft), and that most tend to leave their respective groups within 6 years of joining.

Chart 1. Comparisons and Common Differences Between Street Gangs and Crews

\begin{tabular}{|c|c|c|}
\hline & Street Gangs & Crews \\
\hline Size & Small to Large & Small \\
\hline Structure & Hierarchical/Formal/Semi-Formal & Informal \\
\hline Longevity & Intergenerational & Single Generation \\
\hline Identity & Recognized Name/Colors/Fixed & May Have Name/Loose Identity \\
\hline Territory & Neighborhood/Street & Less Fixed to Location \\
\hline Criminal Behavior & Wide Range/Increased Violence & Less Organized/Reduced Range \\
\hline
\end{tabular}

\section{Discussion}

The current study revealed some valuable findings in regard to the reasons why young people join deviant or criminal groups. In connection to what other research has found in regard to why young people become involved in groups such as street gangs (e.g., Bishop et al., 2017; Densley, 2019), there is a clear connection between early socialization and life experiences, differential association, lack of social control, social learning, and subsequently becoming involved in one of these types of groups. Friendship, family, respect, money, and protection are among the top reasons that young people often become active in criminal groups. The data revealed several common themes that ran across the various deviant groups and key demographic variables. For instance, it is most common for people to become involved in deviant groups when they are in their teenage years $(\overline{\mathrm{X}}=15)$, and to leave their respective groups during their early adult years. Most group members are active in their respective groups for less than 6 years. Other research has found that it is even less than this, ranging from 1 to 2 years on average (Densely, 2019; Weerman et al., 2014). Other studies working with smaller sample sizes have found average active membership rates much higher than this. For example, Berger et al. (2017) found the average membership in a street gang to be 11.6 years $(\mathrm{N}=39)$. This does not seem to be within the normal range of 
duration in these groups and the findings are most likely due to a small sample size that only looked at "core" ex-members; as opposed to more transitory and less invested members. Either way, it is clear that group membership, for the most part, is temporary and more closely linked to early developmental life stages.

The findings from the study also revealed that becoming a member of one of these groups is directly linked to engaging in harmful behaviors. Every study participant disclosed that they were involved in some kind of criminal or destructive behaviors while they were participating in their respective groups. This held across all types of groups regardless of which type of group it was (e.g., street gang, crew, biker gang). This finding is in alignment with earlier research that found that becoming involved with a deviant group increases criminal offending and violent behavior (Bullard \& Reid, 2019; Carson \& Esbensen, 2017; Suh et al., 2016). The most common criminal and harmful behaviors identified in this study involved the use of drugs and alcohol - keeping in mind that 120 out of 124 respondents were juveniles (under 21 years of age) when they joined their respective groups. Following drug and alcohol use, were criminal behaviors associated with graffiti, vandalism, theft, violence, robbery, and burglary. It is plain from the findings that being involved in any of these types of deviant groups is clearly correlated with engaging in harmful and criminal behaviors.

Among some of the top reasons that people decided to leave their groups was because of legal problems, being injured, and being burned out with the lifestyle. Bullard \& Reid (2019) and Pyrooz et al. (2017) found in their work that one of the best times to pull gang members out of their groups was during critical moments (e.g., during emergency services) when they have been seriously injured or have faced some major negative life consequence in some way (e.g., being stabbed, jumped). The decision to leave the group often results from a combination of pushes and pulls (Berger et al., 2017). From the current study it was clear that maturity, family responsibilities, parental responsibilities, legal problems, and employment were the major determinant forces that drove members away from their groups and unhealthy lifestyles. Virtually every study participant stated that they would make different life choices if they were able to turn back time. The vast majority of the former members stated that they would not join their groups if they could do it over again. Almost all of the participants that were still active group members stated that they would still join their groups if they could start over again. Based on the data, it would stand to reason that most of these active members would have a change of opinion if they were asked these same questions after they were no longer in their groups. As identified from prior research (e.g., Goodwill \& Ishiyama, 2016; Macfarlane, 2018), it often takes some seriously harmful life experiences (e.g., being shot, incarcerated, etc.) before deviant group members make the decision to leave their groups. With this considered, $77 \%$ of the respondents stated that joining their respective groups has had a significant impact on their lives. Only $10.5 \%$ of the respondents stated that it had little or no impact on their lives and development.

Even though many youths join deviant groups at some point in their early development, most will grow out of it by their early adult years. There are some important things that can be done to help curb harmful and destructive behaviors among the nation's youth. Healthy family structures and peer relations are central to this problem. Young people that come from dysfunctional, neglectful, and/or violent home environments are much more likely to become involved in a criminal group. Early learning and socialization are core factors when it comes to steering the nation's youth on a healthy life course. Healthy school and classroom environments, as well as positive relations with teachers, is also critical. Young people that are on a deviant life path need caring and older mentors to guide and establish proper scaffolding for their social, cognitive, and behavioral development. Some established programs have also demonstrated efficacy through structured mentoring programs designed to help formerly wayward youth get back onto a healthy life course (e.g., Corely, Dobberteen, \& Willis, 2018).

The ability of the study to make certain claims about certain groups was limited due to having small subgroup sample sizes. It was not possible to run certain statistical analyses due to the fact that the majority of the sample was made up of current and former street gang members and current and former members of crews. To be able to make more inferential statements of confidence about biker gangs, prison gangs, drug gangs, and car crews, it would be necessary to collect information from more respondents representing each of these subgroups. The study's findings may have also been highly affected by the nature of the sample itself. Most of the respondents were under 30 years of age. It may stand to reason that collecting data from former group members that are over 40 years of age may have resulted in very different findings regarding impact of group and thoughts about joining the group. Future research can look further into the causal factors behind joining a deviant group, behaviors while in the group, and forces motivating one to leave the group. Youth deviance and criminal behavior is a serious social problem. Researchers, educators, clinicians, mental health practitioners, and those working in law enforcement should be well aware of what is taking place with all of this.

\section{Conclusion}

This study collected quantitative data from 124 individuals that have identified as being, or having been, a member of a deviant group, such as a street gang. The study found that there are various reasons as to why people join deviant groups. The most common reasons being friendship, respect, family, and money. All of the study participants acknowledged that 
they engaged in some type of criminal behavior while active in their groups. The most common deviant behaviors found in the study involved the use of alcohol and drugs. These common behaviors were followed by graffiti, vandalism, theft, and violence. The findings revealed that the average age at joining was 15 and that most group members are no longer active by 22 . The most commonly identified reasons for leaving their respective groups were due to being arrested and incarceration, being harmed (e.g., stabbed), and disillusionment and fatigue with the lifestyle. The majority of members in this study claimed that their time spent in the group has had a significant impact on their lives. Most of the former members stated that if they could go back in time that they would not join their respective groups. Current members of deviant groups had the exact opposite sentiment. Nearly all of the active members stated that they would join again. This work has brought forth additional information and evidence that add insight and awareness into the attitudes, motivations, and behaviors of deviant group members. The findings of this study may be of use to those working across a range of educational and applied professions that are involved with youth deviance, criminal behavior, and the treatment of offenders.

\section{References}

Bao, W. N. (2018). Strain, coping, and delinquency among different groups of youth. Advances in Criminology and Criminal Justice in China, 1, 181-201. https://doi.org/10.1007/978-3-319-63727-3_6

Beresford, H., \& Wood, J. L. (2016). Patients or perpetrators? The effects of trauma exposure on gang members' mental health: A review of the literature. Journal of Criminological Research, Policy, and Practice, 2(2), 148-159. https://doi.org/10.1108/JCRPP-05-2015-0015

Berger, R., Abu-Raiya, H., Heineberg, Y., \& Zimbardo, P. (2017). The process of desistance among core ex-gang members. American Journal of Orthopsychiatry, 87(4), 487-502. https://doi.org/10.1037/ort0000196

Bishop, A. S., Hill, K. G., Gilman, A. B., Howell, J. C., Catalano, R. F., \& Hawkins, D. (2017). Developmental pathways for youth gang membership: A structural test of the social development model. Journal of Crime and Justice, 40(3), 275-296. https://doi.org/10.1080/0735648X.2017.1329781

Bullard, H., \& Reid, S. (2019). Gangs and violence. Criminology and Criminal Justice, 1, 1-10. https://doi.org/10.1093/acrefore/9780190264079.013.442

Carson, D. C., \& Esbensen, F. A. (2017). Prevalence, risk factors, and pathways to gang violence. The Wiley Handbook of Violence and Aggression. Hoboken, NJ: Wiley \& Sons. https://doi.org/10.1002/9781119057574.whbva101

Corley, C., Dobberteen, D., \& Willis, D. (2018). Meals and mentoring: Former gang members and older adults cross generational and cultural bridges. Innovation in Aging, 2(1), 160-161. https://doi.org/10.1093/geroni/igy023.579

Densley, J. A. (2019). Gang joining. Criminology and Criminal Justice, 3, 1-27. https://doi.org/10.1093/acrefore/9780190264079.013.437

Densley, J. A., \& Pyrooz, D. C. (2017). A signaling perspective on disengagement from gangs. Justice Quarterly, 36(1), 31-58. https://doi.org/10.1080/07418825.2017.1357743

Estrada, J. M., Gilreath, T. D., Sanchez, C. Y., \& Astor, R. A. (2017). Associations between school violence, military connection, and gang membership in California secondary schools. American Journal of Orthopsychiatry, 87(4), 443-451. https://doi.org/10.1037/ort0000181

Federal Bureau of Investigation. (2019, July). What we investigate: Gangs. Retrieved from https://www.fbi.gov/investigate/violent-crimes/gangs

Gallupe, O., \& Gravel. (2017). Social network position of gang members in schools: Implications for recruitment and gang prevention. Justice Quarterly, 35(3), 505-525. https://doi.org/10.1080/07418825.2017.1323114

Gang Reduction and Youth Development (2019, July). Mission: Comprehensive strategy. Retrieved from https://www.lagryd.org/mission-comprehensive-strategy

Garduno, S. L., \& Brancale, J. M. (2017). Examining the risk and protective factors of gang involvement among Hispanic youth in Maryland. Journal of Community Psychology, 45(6), 765-782. https://doi.org/10.1002/jcop.21891

Goodwill, A., \& Ishiyama, I. F. (2016). Finding the door: Critical incidents facilitating gang exit among indigenous men. Cultural Diversity and Ethnic Minority Psychology, 22(3), 333-340. https://doi.org/10.1037/cdp0000061

Los Angeles Police Department (2019, July). Gangs. Retrieved from http://www.lapdonline.org/get_informed/content_basic_view/1396

Macfarlane, A. (2018). Gang and adolescent mental health: A narrative review. Journal of Child \& Adolescent Trauma, 2 , $1-10$. 
Medina, J., Ralphs, R., \& Aldridge, J. (2012). Mentoring siblings of gang members: A template for reaching families of gang members? Children \& Society, 26, 14-24. https://doi.org/10.1111/j.1099-0860.2010.00307.x

Merrin, G. J., Hong, J. S., \& Espelage, D. L. (2015). Are the risk and protective factors similar for gang-involved, pressured-to-join, and non-gang involved youth? A social-ecological analysis. American Journal of Orthopsychiatry, 85(6), 522-535. https://doi.org/10.1037/ort0000094

Pyrooz, D. C., McGloin, J. M., \& Decker, S. H. (2017). Parenthood as a turning point in the life course for male and female gang members: A study of within-individual changes in gang membership and criminal behavior. Criminology, 55(4), 869-899. https://doi.org/10.1111/1745-9125.12162

Roman, C. G., Decker, S. H., \& Pyrooz, D. C. (2017). Leveraging the pushes and pulls of gang disengagement to improve gang intervention: Findings from three multi-site studies and a review of relevant gang programs. Journal of Crime and Justice, 40, 316-336. https://doi.org/10.1080/0735648X.2017.1345096

Schaeffer, R. T. (2018). Sociology: A brief introduction (12 ${ }^{\text {th }}$ ed.). New York, NY: McGraw-Hill.

Suh, C. S., Brashears, M. E., \& Genkin, N. (2016). Gangs, clubs, and alcohol: The effect of organizational membership on adolescent drinking behavior. Social Science research, 58, 279-291. https://doi.org/10.1016/j.ssresearch.2015.12.004

Weerman, F. W., Lovegrove, P. J., \& Thornberry, T. (2014). Gang membership transitions and its consequences: Exploring changes related to joining and leaving gangs in two countries. European Journal of Criminology, 2(1), 70-91. https://doi.org/10.1177/1477370814539070

\section{Copyrights}

Copyright for this article is retained by the author(s), with first publication rights granted to the journal.

This is an open-access article distributed under the terms and conditions of the Creative Commons Attribution license which permits unrestricted use, distribution, and reproduction in any medium, provided the original work is properly cited. 